\title{
Reference guide: Factorial focus group analysis methods for studying social norm change
}

Bettina Shell-Duncan

Amadou Moreau

Katherine Wander

Sarah Smith

Follow this and additional works at: https://knowledgecommons.popcouncil.org/departments_sbsr-rh

Part of the International Public Health Commons, Sociology of Culture Commons, and the Women's Health Commons

How does access to this work benefit you? Let us know!

\section{Recommended Citation}

Shell-Duncan, Bettina, Amadou Moreau, Katherine Wander, and Sarah Smith. 2019. "Reference guide: Factorial focus group analysis methods for studying social norm change." Evidence to End FGM/C: Research to Help Girls and Women Thrive. New York: Population Council. 


\title{
A REFERENCE GUIDE
}

\section{Factorial Focus Group Analysis Methods for Studying Social Norm Change}

The factorial focus group methodology described in this guide provides a powerful means of illuminating the social norms that uphold FGM/C, and the ways in which meanings have at times become contested or rejected. The methods described here can be applied to the study of a wide range of behaviors influenced by social norms, such as early marriage, adoption of contraception, and more.

\author{
Bettina Shell-Duncan, University of Washington, Seattle, Washington, USA \\ Amadou Moreau, Global Research and Advocacy Group, Dakar, Senegal \\ Katherine Wander, Binghamton University, Binghamton, New York, USA \\ Sarah Smith, Global Research and Advocacy Group, Dakar, Senegal
}

\section{OVERVIEW}

Social norms theory has become a prominent framework for understanding the perpetuation of health-related behaviors and generating change through interventions designed to alter practices. Norms perspectives have been used to address a wide range of issues such as eating habits, alcohol consumption, and sexual assault prevention, but one of the best-known applications has been to address the practice of female genital mutilation/cutting (FGM/C). Theoretical advances draw attention to the fact that practices such as FGM/C are often upheld by multiple interconnected norms that may vary and shift over time, offering a potential resource for social transformation.

Focus group interviews produce a distinctive means of generating data that can be particularly useful in exploratory investigations of social norms and the cultural meanings and values with which they are associated. Focus groups are designed to elicit information on perceptions and attitudes, and to provide an opportunity to observe exchanges between participants, as well as their reactions to these exchanges. One particularly powerful comparative approach to focus group methodologies involves factorial designs, which enable a comparison of views across different subgroups. A factorial focus group approach involves holding discussions with separate groups, each homogenous in terms of having common control characteristics, but different in terms of break characteristics - that is, characteristics that differentiate groups from each other. For instance, if one were to use one control characteristic, such as being female, along with two break characteristics, age (30 years and older versus younger than 30 years of age) and location of residence (urban versus rural), four focus group categories are defined: younger urban women, older urban women, younger rural women, and older rural women. By using common guidelines for discussions among different subsets of individuals, it is possible to draw comparisons and look for patterns or variation in cultural meanings and values, and identify when and where norms have become contested or transformed.

Factorial focus group analysis is a powerful method for understanding the constellation of norms and patterns of norm change. It can be used to address the following questions: What is the constellation of norms associated with $\mathrm{FGM} / \mathrm{C}$ ? When are existing practices and norms being contested? And, how does this reflect prevailing structures of power and authority? By identifying the people who are best positioned to serve as potential change leaders, and drawing on variability and fluidity in social norms, it may be increasingly possible to design interventions that will shape possibilities for action and accelerate abandonment of FGM/C without undermining the cultural value of tradition. 
The purpose of this document is to guide researchers who plan to use factorial focus group analysis methods, drawing on our experiences implementing the Senegambia Behavior Change Study on Female Genital Cutting.

\section{INTRODUCTION TO SOCIAL NORMS}

Social norms theory has become a prominent framework for understanding health-related behaviors, and in recent years has been influential in the design of interventions aimed at generating social change. Norms perspectives have been used to address a wide range of issues such as eating habits (Rah et al. 2004), alcohol consumption (Campo et al. 2004), safer sex, and sexual assault prevention (Scholly et al. 2005). Norms are customary rules of behavior shared by members of a reference group and characterized by reciprocal expectations-individuals follow the rule based on the expectation that others follow the social rule, and that expectations are mutual (Biccieri 2005). These include empirical expectations, which are based on how individuals see others in their reference group (that is, their social network) behaving. They also include normative expectations, which are based on people's belief that the social rule ought to be followed or will be actively enforced through sanctions. The interaction of individuals makes conforming in their best interest.

A particularly well-known application of social norms theory has been to the practice of FGM/C (UNICEF 2013). A model first developed by political scientist Gerald Mackie (1996), posited that FGM/C is a social norm that spread and became locked in place by interdependent expectations regarding marriageability. This model delineated the ways in which individuals are not capable of acting upon their own intentions without coordinating change among individuals with interdependent expectations. Drawing an analogy with footbinding in Imperial China, Mackie suggested that both practices originated in highly stratified ancient empires under conditions of extreme resource inequality. Mackie hypothesized that both $\mathrm{FGM} / \mathrm{C}$ and footbinding served as a strategy to move up into highly stratified socioeconomic classes by improving women's chances of marriageability to a small number of elite males with multiple wives. In this context where paternity certainty is an important concern, both practices served to signal fidelity control. Mackie posited that in the competition for marrying into higher social strata, FGM/C became a universal prerequisite for marriage, and persisted even after the originating conditions of extreme resource inequality and polygyny vanished.
However the custom originated, as soon as women believed that men would not marry an unmutilated woman, and men believed that an unmutilated woman would not be a faithful partner in marriage, the convention was locked in place. A woman would not choose nonmarriage and not to have her own children; a man would not choose an unfaithful partner and not to have his own children (Mackie 2000: 264).

In describing $\mathrm{FGM} / \mathrm{C}$ as a social coordination norm, Mackie $(1996,2000)$ drew upon the work of Schelling (1960) to explain the dynamics of the perpetuation of the practice through game theory. Game theory addresses decisionmaking that is relational and interdependent; what one person chooses to do depends on the choices of others. Once locked in place, $\mathrm{FGM} / \mathrm{C}$ as a prerequisite to marriage operates as a social coordination norm. Individuals opting out pay the high price of losing marriageability and legitimate childbearing. However, if a group of intermarrying families were persuaded that being uncut is better than being cut and would not preclude marriage, change could be coordinated without social sanctions. For this to occur, individuals must be provided with credible information to become aware of an alternative. They must also have an opportunity to discuss the new information and to become convinced both that it is a viable option and that a sufficiently large number of others will abandon the practice so as not to be penalized for their decision. To change the condition, it is necessary to coordinate abandonment among intermarrying.

Mackie $(1996,2000)$ noted that at the outset, it is not necessary to have unanimous agreement by all community members. He suggested that a relatively small core group-a critical mass - can initially agree to abandon FGM/C. This provides a clear element for the design of intervention strategies: abandonment must be coordinated among a critical mass of intermarrying families, and the commitment to abandonment must be effectively, publicly communicated.

With subsequent empirical investigations, as well as a growth in scientific literature on social norms, views on norms related to FGM/C have expanded. Newly emphasized is the fact that $\mathrm{FGM} / \mathrm{C}$ may be held in place not only by norms related to marriageability, but also by a wide range of norms and associated meanings that may center on concerns including peer pressure, ethnic identity, adolescent rites of passage, religion, honor, modesty and sexual restraint, aesthetics, and hygiene (Mackie and LeJeune 2009). 


\section{TYPOLOGY OF NORMS}

The varied forms that sanctions for norm violation may take have been used to create a typology of norms, differentiating social, legal, religious, and moral norms (Mackie and LeJeune 2009) (Table 1). These are best understood by examining the reasons why individuals conform to a practice. Social norms are enforced by intrinsic motivation generated by a desire to conform with perceived social expectations, and through sanctions that are either positive rewards for adherence or negative punishments; people conform to social norms to gain rewards or avoid sanctions. In The Gambia, for example, women who have undergone FGM/C are said to "know the eye," a term that refers to having been trained to display nonverbal signs of deference and respect to elders (Shell-Duncan et al. 2011). These women are widely regarded as behaving in a fashion that is socially refined and rewarded with social approval. By contrast, women who have not undergone FGM/C are often taunted by being called solema, a powerful invective that means not only uncut, but also dirty, ignorant, and rude (ShellDuncan et al. 2011). For uncut women with co-wives who have undergone $\mathrm{FGM} / \mathrm{C}$, negative sanctions serve as a major source of tension in intrafamily conflict; uncut women are often excluded from household decisionmaking and participation in ceremonies, and at times co-wives refuse to eat the food they cook. This day-to-day pressure has, in a handful of instances, led to adult women electing on their own to undergo FGM/C. One informant reported, "I was so sick and tired of the isolation and insults that the Mandinka women gave us, it was like I did not notice the pain much. And just after the event [FGM/C] my co-wife congratulated me for being so brave and also presented me with some gifts of gold earrings and a ring" (Hernlund and Shell-Duncan 2007: 52).

While social norms are unwritten rules that stem from beliefs about what constitutes typical and appropriate behaviors in a group, gender norms are a subtype of social norms related to gender difference regarding acceptable behavior of men or women and gender roles in a particular society (Cislaghi and Heise 2018). Gender norms are shaped by the process of gender socialization and create expectations for what is considered appropriate behavior for upholding ideals linked to masculinity or femininity in different social arenas-at home, in the community, in school or the workplace, and in interpersonal relationships. Discriminatory gender norms limit girls' and women's access to power within their families and communities, reduce their educational and economic
TABLE 1. TYPOLOGY OF NORMS

\section{Social norms (including gender norms)}

Enforced by intrinsic motivation to conform with perceived social expectations, and by positive or negative social sanctions; a subset of social norms may be gender norms (social expectations on roles, behavior, and attitudes that vary by gender)

\section{Legal norms}

Enforced by government sanctions formally stated in law (fines or imprisonment)

\section{Religious norms}

Enforced by belief in love or fear of God

\section{Moral norms}

Enforced by emotions evoked by internalized values of right and wrong

opportunities, and alter their own aspiration and ambitions for their lives.

Legal norms, like social norms, enforce compliance through sanctions. However, legal norms are formally stated in law, and are enforced through government sanctions such as fines and imprisonment. The formal specification of punishment is intended to serve as a deterrent to performing a behavior that has been classified as criminal or deviant (Levinson 2002). General deterrence focuses on creating social change that reduces the likelihood of transgression by creating fear of detection and punitive consequences. This is often accomplished by educating the public about the law and making punishment public to create the impression that apprehension and punishment are likely and severe.

When legal norms run counter to social norms, legislative reform may have limited, conflicting, or unintended consequences (Shell-Duncan et al. 2013). Research in Senegal, for instance, demonstrated that the 1999 ban on FGM/C produced mixed responses. Although the law was widely viewed as enforceable, fear of sanctions in some cases motivated abandonment, and in others drove the practice underground. Additionally, some individuals chose to openly defy the ban, arguing that the law was an attempt to "break culture" (Shell-Duncan et al. 2013). Beyond the threat of legal sanctions, other important factors influence behavior, including the opinion of peers, personal morals, and perception of legitimacy of the law and legal authorities (Tyler 
1990). Additionally, if a legal ban runs counter to a strongly held social norm, enforcement of the law is questionable, as law enforcement officials and judges may feel pressure to uphold the social norm. It is becoming clear that legal measures in isolation have limited success in promoting behavioral and social change.

When social norms are being contested, legal bans can be useful in supporting the change process. The backing of a legal system gives added power to those social norms that are consistent with legal norms. McAdams (2000) adds that legislation may serve to communicate a change in preferences in a community and affect behavior "expressively" by what it says rather than what it does (sanctions). Educating the public about the existence of a new law may serve this communication purpose. Additionally, once behavior change is in place, legal provisions can create an "enabling environment," providing support for those who have adopted the new behavior (UNICEF 2005: 29).

Mackie and LeJeune (2009: 20) describe religious norms as "commanded by God and obeyed by the believer out of love and fear of the deity." In areas where FGM/C is common, it is performed by Christians, Muslims, and Jews, as well as members of non-Abrahamic religions. Religion, tradition, and culture are deeply intertwined in some settings, allowing FGM/C to be interpreted as a religious obligation. Even though FGM/C predates the birth of Islam and Christianity and is not mandated by religious scriptures, the belief that $\mathrm{FGM} / \mathrm{C}$ is a religious requirement operates as an important factor in several settings. For instance, among Mandingas in Guinea Bissau, FGM/C has become inextricably linked to Islamic identity formation; the practice is widely considered to be a prerequisite for ritual purity necessary in order to to pray, as well as a marker of belonging to an Islamic community (Johnson 2000). Members of Mandinga migrant communities in Portugal are, however, exposed to "modern" Islam (as understood and practiced by those outside Africa) whose members largely do not practice FGM/C. Johnson (2007) describes how this has led many to create a distinction between religion and culture, and in some instances call the practice of FGM/C into question. This illustrates how various norms are often interconnected, and that changes in one norm can influence associated norms. Conversely, where religious norms remain firmly in place, failure to address this issue may impede change efforts.

Moral norms, like social norms, are widely accepted by individuals and generate social regularities. They do not, however, do so through external sanctions, but rather through internalized values of right and wrong, which result in compliance even if not observed or enforced by others (McAdams 1997). Scholars have emphasized that while exogenous social sanctions can play a role in enforcing norms, much conformity appears to be endogenously motivated by emotions. These include a feeling of righteousness for compliance, or a feeling of guilt or shame for noncompliance (Boyd and Richerson 1992; Fessler 2004). Fessler (2004) argues that in highly hierarchical societies, subordination is associated with a culturally shaped emotion of shame. This powerful emotion helps explain why girls may individually opt to undergo FGM/C. Writing on the Meru of Kenya in the 1950s, Thomas (2000: 136) describes the role that FGM/C played in elaborating political hierarchies across generations of women. Her account reveals how female initiation "not only remade girls into women, it transformed women into figures of authority within the community." Following a 1956 ban on clitoridectomy, adolescent girls defied the ban by performing FGM/C on one another. While peer pressure may have served as an external sanction, it is likely that the shame and stigma associated with being uncut contributed to this self-motivated action.

Mackie and LeJeune (2009) explain that the originating conditions for FGM/C need not remain static. The practice may begin as a social convention, become both a norm and a convention, and later become maintained only through social norms. Michelle Johnson, writing about the Mandinga in Guinea Bissau, finds that FGM/C is currently not tied to concerns about marriageability, but is strongly tied to concepts of personhood and religious identity (2000). An ethnographic account from the 1940s, however, reveals that FGM/C was linked to marriageability in earlier generations (Carreira 1947, cited in Johnson 2000: 219). Mackie and LeJeune (2009) emphasize the need to identify the suite of conventions and norms that can hold the practice of FGM/C in place, and to provide credible information from trusted sources that is tailored to the local context and meanings of the practice.

\section{FLUIDITY AND CHANGE IN SOCIAL NORMS}

It is useful to tease apart the constellation of norms and conventions that reinforce $\mathrm{FGM} / \mathrm{C}$ to gain insights into the diversity of ways that the practice is enforced or upheld. Gruenbaum emphasizes that "[u]nderstanding the diversity of reasons is the central issue if there is to be any hope for cross-cultural understanding, fruitful dialogue, or effective change efforts" (Gruenbaum 2001: 33). At the same time, 
she stresses the importance of recognizing that these multiple factors do not operate in isolation, but rather are intricately intertwined in complex sociocultural systems, more analogous to cogs in a machine, threads in a tapestry, or organs in a body. As such, changes in one element of the system often have cascading effects, and sometimes unforeseen consequences for social institutions. Changing practices regarding girls' education, for instance, may have other effects such as delaying marriage or FGM/C. This, in turn, may generate cultural resistance from those who see this as undermining morality or family honor, as such delays may elevate the risk of premarital pregnancy or resistance to arranged marriages. Nevertheless, taking the engine of culture down to its constituent parts is useful as it enables analysts to identify parts that can be modified or are currently being challenged. It is possible to examine the ways in which social movement is being generated by the internal stresses of society, such as marriage traditions that become viewed as outdated under global influences, as well as the influences of social reform efforts. It becomes possible to see aspects of culture that are being contested, and inconsistencies that may arise in social, moral, and legal norms in changing cultural systems.

Theoretical perspectives of the role of social context in behavior change have become enriched by anthropological research that illuminates the way that historical and structural factors interact with interpersonal interactions and personal goals, and the way in which cultural variation provides the raw material for meeting these goals (An-Na'im and Hammond 2002; Burke et al. 2009; Cowan, Dembour, and Wilson 2001; Merry 2006). This work extends an earlier body of scholarship that challenged understandings of culture as static and deterministic of behaviors. From this viewpoint, FGM/C had become labeled a "harmful traditional practice," and adherents of the practice were understood to lack agency to interpret culture, evaluate options, and make genuine choices. Culture was cast as a justification for following customs rooted in the past, posing a barrier to social transformation and reform efforts. An alternative perspective points to the diverse views and multiple meanings associated with $\mathrm{FGM} / \mathrm{C}$, and the dynamic process through which shared meanings and social knowledge are generated (Gruenbaum 2005). Emphasized are the fluidity of social norms and cultural values, and the contexts in which FGM/C becomes associated with meanings that can accrue, be lost, or altered, thereby influencing whether and how FGM/C is practiced. This understanding offers that social norms and associated meanings are neither static nor homogenous, but instead varied and constantly changing through processes of cultural borrowing and innovation (Abdelshahid and Campbell 2015; An-Na'im and Hammond 2002; Cowan et al. 2001; Merry 2001, 2006). Rather than being purely prescriptive, culture offers a range of options that define acceptable and unacceptable courses of action. An-Na'Im and Hammond (2002) offer the image of a "cultural tool kit" from which individuals construct strategies of action to meet their goals, while Hernlund (2003) uses the metaphor of a winnowing basket to describe the process in which people actively negotiate which aspects of culture should be retained or discarded in light of current or shifting social realities. Recent theoretical advances in behavior change draw on these insights about social context, personal interactions and goals, and cultural variation to suggest strategies for guiding social transformation (An-Na'im and Hammond 2002; Merry 2006). Seeing culture as varied and fluid allows for the interpretation of cultural heterogeneity as an indigenous "resource for change" rather than a repository for unchanging patriarchal values (Merry 2006: 9; see also Nyamu-Musembi 2002; Vogt et al. 2016).

Drawing on these theoretical perspectives, the goal of this reference guide is to highlight a powerful analytical approach-factorial focus group analysis - for exploring the social norms and dynamics that influence decisionmaking regarding practices such as FGM/C. We draw on our experiences implementing the Senegambia Behavior Change Study on Female Genital Cutting. The key questions we asked are: What is the constellation of norms and meaning associated with a practice such as FGM/C? In what ways are the norms being shaped, upheld, resisted, or modified in light of changing social circumstances? When and where are existing practices and norms being questioned, and how does this reflect prevailing structures of power and authority?

\section{FACTORIAL FOCUS GROUP METHODOLOGY FOR THE STUDY OF SOCIAL NORMS AND DYNAMICS OF CHANGE}

The growing focus on social norms perspectives has generated interest in understanding how to identify social norms, along with the social contexts and cultural factors that shape them. Differing from legal norms, whose proscriptions and violations are explicitly codified, social norms are unwritten rules governing behaviors within particular social groups. They are held in place by beliefs about acceptable and unacceptable courses of action that can, to varying degrees, shape and constrain the choices made by community members, and are produced, transmitted, and 
often enforced through social interactions (Mackie et al. 2015). As such, it is possible to shed light on norms through research approaches that include social interactions as an object of inquiry.

Focus group interviews produce a distinctive means of generating data that can be particularly useful in exploratory investigations of social norms and the cultural meanings and values with which they are associated (Gruenbaum 2001). Focus groups are structured, planned group interviews that are designed to elicit information on perceptions and attitudes, and provide an opportunity to observe exchanges between participants, as well as their reactions to these exchanges. This approach generates useful information in several ways: What topics were raised in a particular group discussion? To what extent is there consensus or disagreement? What reactions were generated by divergent perspectives?

Unlike in-depth interviews, focus group methodologies are not well suited to explore the experiences and histories of individuals. For instance, questions about how an individual arrived at a decision as to whether, when, or how their daughter should undergo FGM/C is a topic best suited for individual interviews. By contrast, focus groups are guided by semi-structured questions that serve as prompts for open-ended small group discussions. They allow participants to describe in detail understandings of cultural practices, preferences, and values found within a community, along with perspectives on the circumstances and debates that frame certain issues. An important part of this process is to allow participants to raise issues and explanations they deem to be salient. For instance, while eliciting information on the meanings associated with $\mathrm{FGM} / \mathrm{C}$, the topics raised may vary across a series of focus groups, reflecting differences in the issues and concerns that participants hold most central. The dialogue among participants offers opportunities for critical reflection on deeper meanings and may reveal divergent views that can spark debate or disagreement. The topics raised reflect the constellation of norms and cultural meanings, and exchanges between participants shed light on the degree to which they have become expanded, altered, or contested.

Participant observation, like focus group methods, affords an opportunity to examine social interactions that can shape cultural values and normative expectations. While participant observation bears the advantage of observing interactions in naturalistic setting, it can be difficult to gain access to settings in which a substantial set of interactions can be observed on the topic of interest (Bernard 2011). Focus group methodologies provide an opportunity to observe a large amount of interactions, and while they do not occur in naturalistic settings, this limitation is also a strength: they allow researchers to exercise control over group discussions, and to hold a series of discussions to generate information that can identify patterns across segments of a community.

One particularly powerful comparative approach to focus group methodologies involves factorial designs (Bernard 2011; Knodel 1993; Shell-Duncan et al. 2018). When there is interest in comparing views across different subgroups, this approach involves holding discussions with separate groups, each homogenous in terms of having common control characteristics, but different in terms of break characteristics - that is, characteristics that differentiate groups from each other (Knodel 1993; Shell-Duncan et al. 2018). Break characteristics are used as the basis for developing a factorial design. For instance, if one were to use one control characteristic, such as being female, along with two break characteristics, age (30 years and older versus younger than 30 years of age) and location of residence (urban versus rural), four focus group categories are defined: younger urban women, older urban women, younger rural women, and older rural women. By using common guidelines for discussions among different subsets of individuals, it is possible to draw comparisons and look for patterns or variation in cultural meanings and values and identify when and where norms have become contested or transformed. If desired, this variation can be quantified by creating survey tools informed by focus group findings (Shell-Duncan et al. 2010).

\section{HOW TO DESIGN AND IMPLEMENT A FACTORIAL FOCUS GROUP DESIGN}

In the study design phase, identify break characteristics (characteristics that will differentiate each group). This might be separating groups along the lines of age (younger versus older), gender (men versus women), marital status (unmarried versus married), region of residence (different regions, or urban versus rural). Also, identify the control characteristics (characteristics that are common to all members of your focus group discussion [FGD]). Examples of control characteristics might be coming from a family that once practiced FGM/C, or ethnicity. Researcher designers should be careful to limit the number of break characteristics because more characteristics require a larger number of focus groups. For instance, if one has two break characteristics, such as gender (men versus women) and two sites (urban versus rural), the minimum number of 
TABLE 2. FOCUS GROUP GUIDELINES FROM THE SENEGAMBIA BEHAVIOR CHANGE STUDY ON FEMALE GENITAL CUTTING

1. What are the advantages of FGM/C? (probe: For girls? For women? For fathers? For husbands?)

2. What are the disadvantages of FGM/C? (probe: For girls? For women? For fathers? For husbands?)

3. What are the solutions?

4. What changes have you seen in the practice of $F G M / C$ ? (probe: stop cutting, reduce severity of cutting, younger age at cutting, medicalization, lack of ritual or public ceremony, other)

5. How do you feel about these changes?

Source: Shell-Duncan et al. 2018.

FGDs is four (1. urban men, 2. rural men, 3. urban women, 4. rural women). If generation is also included (older versus younger), the minimum number of FGDs increases to eight (1. younger urban men, 2. older urban men, 3. younger urban women, 4. older urban women, 5. younger rural men, 6 . older rural men, 7. younger rural women, 8. older rural women).

All focus groups should follow common guidelines for the moderator of the discussion. Focus group guidelines should be designed to elicit normative statements by prompting discussion on attitudes and options about, say, FGM/C, as well as perceptions of behavioral patterns. The guidelines should use broad questions, allowing respondents to raise the issues that are relevant in their view. The guidelines used in the Senegambia Behavior Change Study on Female Genital Cutting (Table 2) illustrates this approach.

The questions and probes were designed to be sufficiently open-ended to allow discussants to raise topics and perspectives that they considered salient. This allows analysts to see topics (norms) that are not relevant to some groups but are relevant to others. Responses are also used to explore the degree to which norms are shared or contested by analyzing both positive and negative associations reported by respondents, and group members' degree of consensus around these evaluations. Each FGD should have six to eight participants to allow for rich discussions and observations of interactions.

Focus group discussions should be convened by two trained fieldworkers. One fieldworker moderates the discussion, while the other digitally records the session and takes notes to guide transcription of recordings. The fieldworkers

\section{KEY STEPS IN FACTORIAL} FOCUS GROUP DESIGN

1. Identify control characteristics, that is characteristics that are common to all participants in all focus group sessions.

2. Identify break characteristics, that is, characteristics that are unique to different focus group sessions (for example, older versus younger, male versus female).

3. Design focus group guidelines that have general, open-ended questions with probes. Use these same guidelines for all focus group sessions.

4. Train moderators to encourage open, even participation, and to not lead the participants to raise any particular topic. Topics not raised are as meaningful as those deemed salient for discussion.

should be fluent in local languages and permit participants to conduct discussions in their language of choice. They should be trained to address and attempt to mitigate wellknown problems in FGDs: there is a risk that one or two participants could dominate a discussion, or that critical comments may silence members whose views are not shared by other discussion participants. Facilitators should be trained to encourage open and even participation, and to create a supportive and respectful atmosphere that permits open sharing and exploration of a range of opinions. Because some statements cannot be interpreted at face value, but instead require interpretation based on the context in which they are made, fieldworkers should provide a descriptive debriefing following each session. Additionally, once the recordings are translated and transcribed, the fieldworkers can add comments describing statements such as jokes, statements with double meaning, segments where respondents seemed reticent or uneasy, and any other relevant observations they can offer from "closeness" to the data that aid in interpretation and analysis of transcripts.

\section{HOW TO ANALYZE FACTORIAL FOCUS GROUP DATA}

We describe five steps in analysis of focus group data collected using a factorial design. These steps are: 
TABLE 3. POSSIBLE WAY TO CODE FOR EMPHASIS AND CONSENSUS (POSITIVE OR NEGATIVE) OR DISAGREEMENT ${ }^{1}$

$+\quad$ Raised with little emphasis, but positive consensus

- $\quad$ Raised with little emphasis, but a negative consensus (e.g., FGM/C is not a prerequisite for marriage)

$++\quad$ Raised with moderate emphasis, with positive consensus

$++\quad$ Raised with great emphasis, with positive consensus

+/- $\quad$ Raised with moderate emphasis, but disagreement

+++ - Raised with strong emphasis, and disagreement

--- $\quad$ Raised with strong emphasis, and a negative consensus

1) coding, 2) creating summary documents, 3) creating an overview grid, 4) creating descriptive memos, and 5) creating an analytic memo for each overarching theme and its subthemes.

\section{Coding}

Once transcripts are reviewed for completeness and clarity, and all queries are resolved, the transcripts are coded (NVivo and ATLAS.ti are two widely used software packages for coding). Begin with a close reading and open coding of the transcripts, double-coding the first three transcripts (that is, have two people code the first three transcripts separately). Members of the analysis team can then meet to compare and reconcile coding strategies and work together to build a list of codes and sub-codes (the code book). The first round involves topic coding that labels key topics. This is followed by a round of analytical coding that begins to group topics along the line of themes (Richards and Morse 2007). In a rapid assessment, it is possible to do step two first (creating a summary document, below) and code the summary document.

\section{Create a summary document of each FGD}

A summary document should be created for each FGD, identifying the major themes raised, grouped along the lines of the major prompts of the FGD guidelines. The summaries will record the major topics raised in response to the focus
KEY STEPS IN THE ANALYSIS OF

\section{FACTORIAL FOCUS GROUP DATA}

1. Code the data using descriptive and analytic codes.

2. Create a summary document for each FGD that lists two things: a) the topics raised, and b) the degree of emphasis and consensus placed on each topic.

3. Create an overview grid that allows for comparison of the FGM/C summaries along break characteristic lines.

4. Identify emerging themes, and the patterns in which they are raised or not raised, and the way they are discussed by FGD participants. Note similarities and differences across break characteristics. Include exemplar quotes in a descriptive memo.

5. Group themes into clusters of overarching themes. Write an analytic theme that identifies the themes in relation to social norms. Note the patterns in which norms are being upheld, are contested, or are absent.

group prompt questions. They will also note: a) the emphasis placed on each theme (ranging from being a passing remark to a topic that participants deeply explored), and b) the degree of consensus, debate, or disagreement that came about during the discussion. A summary template is shown in Appendix A. An example summary from the Senegambia Behavior Change Study on Female Genital Cutting is shown in Appendix B. A possible scheme for coding emphasis and consensus or disagreement is shown in Table 3.

This process serves as an analytic approach to discerning the degree to which normative statements and positive or negative associations are shared among participants, debated, or possibly actively contested during the discussion.

We recommend using a team approach to both creating data summaries and identification of themes to improve reliability of the analysis. The data analysis team members can independently identify topics and patterns, and then meet to discuss interpretation of emerging themes, and to identify "exemplar quotes" — direct quotes from the

\footnotetext{
${ }^{1}$ Negative consensus arises when a norm has shifted and people agree with this shift. For example, in the past, FGM/C may have been a prerequisite in the study community. Now, most people in this communities agree that FGM/C is no longer a prerequisite.
} 
TABLE 4. SUMMARY MATRIX OF THEMES RELATED TO THE OVERARCHING THEME OF UPHOLDING SOCIAL HIERARCHY (SOURCE: SHELL-DUNCAN ET AL. 2018)

\begin{tabular}{|c|c|c|c|c|c|c|}
\hline & \multicolumn{2}{|c|}{ Urban Gambia } & \multicolumn{2}{|c|}{ Rural Gambia } & \multicolumn{2}{|c|}{ Rural Senegal } \\
\hline & $\begin{array}{l}\text { Younger } \\
\text { women }\end{array}$ & Older women & $\begin{array}{l}\text { Younger } \\
\text { women }\end{array}$ & Older women & $\begin{array}{l}\text { Younger } \\
\text { women }\end{array}$ & Older women \\
\hline Respect for elders & + & + & + & + & + & + \\
\hline Training (to "know the eye") & + & + & + & + & + & + \\
\hline $\begin{array}{l}\text { Authority to challenge } \\
\text { FGM/C }\end{array}$ & - & $+/-$ & - & $+/-$ & & $+/-$ \\
\hline
\end{tabular}

+ positive consensus

+/- divergent views

- negative consensus

Blank-theme not raised

transcripts that illustrate a concept or theme (Bernard 2011). The starting point for this analysis is assessing the degree with which stated representations and understandings of FGM/C are shared, contested, or contradicted (by individual respondents themselves or between participants), reflecting ambivalence by at last some members of the discussion group. A key element in this analysis is exploring the possibility that practices, meanings, and values associated with $\mathrm{FGM} / \mathrm{C}$ may not be fixed and shared among all participants. Instead, one can explore the possibility of potentially shifting, and at times inconsistent or contested views on $\mathrm{FGM} / \mathrm{C}$.

The summaries should be no more than one to two pages in length.

\section{Create an overview grid with the summaries for making comparisons across FGDs}

The summaries for each focus group are next used to create an "overview grid" following established methods (Knodel 1993; Shell-Duncan et al. 2018), allowing comparisons along the lines of break characteristics (such as younger versus older, men versus women, and location of residence-urban versus rural, different regions, or different ethnicity). There are several items of interest in analysis of the overview grid: What themes were common across focus groups? What themes were unique to certain groups? What was most emphasized in different groups? Where did disagreements emerge?

The overview grid is a matrix of the FGD summaries. This can be done using a program such as Atlas.ti, but it is often useful to simply print out the summaries, and arrange them side-by-side, allowing the research team to discuss patterns and themes.

\section{Create a descriptive memo that groups related themes} Writing memos is an important tool in qualitative analysis. We recommend using a two-step approach in the creation of memos. The first is a descriptive memo that groups related themes under the umbrella of an overarching theme. Which themes fit together? How are they inter-related? As you explain this, you can draw on select illustrative quotes from your summaries.

This tends to be an iterative process. Original groupings may need to be revised as linkages become clearer in the process of writing the memo. An example of a descriptive memo from the Senegambia Behavior Change Study on Female Genital Cutting is shown in Appendix C.

\section{Create an analytic memo for each overarching theme and its subthemes}

Once basic themes are grouped into overarching themes, a summary matrix is created for each overarching theme (Miles and Huberman 1994). This matrix summarizes the direction of consensus as follows: positive consensus among discussants $(+)$, negative consensus (-), divergent views (+/-), or a theme not raised (blank). An example of a summary matrix from the Senegambia Behavior Change Study on Female Genital Cutting is shown in Table 4.

Analytic memos move beyond description of themes that emerged through the earlier analysis to looking for patterns and interpreting the results through the lens of social norms theory. The subthemes represent possible social, moral, legal, or religious norms, and provide a visual display for 
understanding the patterns in which norms are being upheld, challenged, or changed. For more information on analytic memos and displays for qualitative data, see (Bernard 2011; Miles and Huberman 1994; Richards and Morse 2007). An example of an analytic memo from the Senegambia Behavior Change Study on Female Genital Cutting is shown in Appendix D.

\section{DISCUSSION}

The factorial focus group methodology described in this report provides a powerful means of illuminating the social norms that uphold FGM/C, and the ways in which meanings have at times become contested or rejected. The methods described here can be applied to the study of a wide range of behaviors influenced by social norms, such as early marriage, adoption of contraception, and more. This methodology allows analysts to examine the fluidity of norms, meanings, and values, resulting in what Hernlund and Shell-Duncan (2007: 45) described as "ever-shifting cultural menus from which people construct their cultural repertoires regarding FGM/C." Increasingly, scholars have emphasized that if culture is viewed as a set of practices and meanings shaped by context and open to change, local norms may be viewed not as an impediment, but instead as resource for change (An-Na'im and Hammond 2002; Merry 2001, 2006). Vogt and colleagues concur, arguing that "programmes that take local heterogeneity as a starting point for promoting abandonment offer a promising avenue for cultural change" (Vogt et al. 2016: 15). At the same time, however, it is important to pay close attention to the structures of power that influence the dynamics of change. By this means, research can draw attention to the community members who are best positioned to realize the dual goal of honoring cultural traditions and values while negotiating change.

\section{IMPLICATIONS FOR INTERVENTIONS}

By drawing on information on the heterogeneity in cultural meanings and values, and the ways in which they are being reassessed in light of shifting social realities, it is possible to draw on cultural variability as a tool for guiding action and social transformation. The identification of advocates for change as well as variability and fluidity in norms and practices opens the possibility of building on social change processes that are underway and may be amenable to alignment with the goal of abandonment of FGM/C.

\section{REFERENCES}

Abdelshahid, A. and C. Campbell. 2015. " 'Should I circumcise my daughter?' Exploring diversity and ambivalence in Egyptian parents' social representations of female circumcision," Journal of Community and Applied Social Psychology 25: 49-65.

Ahmadu, F. 2005. Cutting the Anthill: The Symbolic Foundations of Female and Male Circumcision Rituals among the Mandinka of Brikama, The Gambia. Ph.D. Doctoral Dissertation, London: London School of Economics.

An-Na'im, A.A., and J. Hammond. 2002. "Cultural transformation and human rights in African societies," in A.A. An-Na'im (ed.), Cultural Transformation and Human Rights in Africa, pp. 13-37. New York: Zed Books Ltd.

Bernard, H.R. 2011. Research Methods in Anthropology: Qualitative and Quantitative Approaches. 5th Ed. Lanham, MD: AltaMira Press.

Bicchieri, C. 2005. The Grammar of Society: Nature and Dynamics of Social Norms. Cambridge: Cambridge University Press.

Boyd, R. and P.J. Richerson. 1992. "Punishment allows the evolution of cooperation (or anything else) in sizable groups," Ethnology and Sociobiology 13(3): 171-195.

Burke, N. J.G. Joseph, R.J. Pasick, and J.C. Barker. 2009. "Theorizing social context: Rethinking behavioral theory. Health Education and Behavior 36(5 Supplement): 55s-70s.

Campo, S., K.A. Cameron, D. Brossard, and M.S. Frazer. 2004. "Social norms expectancy violation theories: Assessing the effectiveness of health communication campaigns," Communication Monographs 71: 488-470.

Cislaghi, B. and L. Heise. 2018. "Using social norms theory for health promotion in low-income countries," Health Promotion International, doi: 10.1093/heapro/day017.

Cowan, J.K., M.-B. Dembour, and R. Wilson, R. (eds.). 2001. Culture and Rights: Anthropological Perspectives. Cambridge: Cambridge University Press.

Fessler, D. 2004. "Shame in two cultures: Implications for evolutionary approaches," Journal of Cognition and Culture 4(2): 207-262.

Gruenbaum, E. 2001. The Female Circumcision Controversy: An Anthropological Perspective. Philadelphia: University of Pennsylvania Press.

2005. "Sociocultural dynamics of female genital cutting: Research findings, gaps and directions," Culture, Health and Sexuality 7(5): 429-441.

Hernlund, Y. 2003. Winnowing Culture: Negotiating Female "Circumcision" in The Gambia. Ph.D. Dissertation. Seattle: University of Washington,. 
Hernlund, Y. and B. Shell-Duncan. 2007. "Contingency, context and change: Negotiating female genital cutting in The Gambia and Senegal," Africa Today 54(4): 43-57.

Johnson, M. 2000. "Becoming a Muslim, becoming a person: Female "circumcision," religious identity, and personhood in Guinea-Bissau," in B. Shell-Duncan and Y. Hernlund (eds.), Female "Circumcision" in Africa: Culture, Controversy, and Change, pp. 215-234. Boulder, CO: Lynne Reinner Publishers.

2007. "Making Mandinga or making Muslims? Debating female circumcision, ethnicity, and Islam in Guinea-Bissau and Portugal," in Y. Hernlund and B. Shell-Duncan (eds.), Transcultural Bodies: Female Genital Cutting in Global Context, pp. 202-223. Piscataway, NJ: Rutgers University Press.

Knodel, J. 1993. "The design and analysis of focus group studies: A practical approach," in D.L. Morgan (ed.), Focus Groups: Advancing the State of the Art, pp. 35-50). Newbury Park, CA: Sage Publications.

Mackie, G. 1996. "Ending footbinding and infibulation: A convention account," American Sociological Review 61: 999_ 1017.

2000. "Female genital cutting: The beginning of the end." in B. Shell-Duncan and Y. Hernlund (eds.), Female "Circumcision" in Africa: Culture, Controversy, and Change, pp. 253-283. Boulder, CO: Lynne Rienner Publishers.

Mackie, G., and J. LeJeune. 2009. Social Dynamics of Abandonment of Harmful Practices: A New Look at the Theory. Innocenti Working Paper No. 2009-06, Florence, Italy: UNICEF Innocenti Research Centre.

Mackie, G., F. Moneti, H. Shakya, and E. Denny. 2015. What are Social Norms? How are they Measured? UNICEF/University of California, San Diego, Center on Global Justice Retrieved September 1, 2014 from http:/www.academiaedu/2007416/ What_are_social_norms_How_are_they_measured.

McAdams, R.H. 2000. "An attitudinal theory of expressive law," Oregon Law Review 79: 339-390.

Merry, S.E. 2001. "Changing rights, changing culture," in J.K. Cowan, M.-B. Dembour, and R. A. Wilson (eds.), Culture and Rights: Anthropological Perspectives, pp. 31-55. Cambridge: Cambridge University Press.

- 2006. Human Rights and Gender Violence. Chicago: The University of Chicago Press.

Miles, M. and A. Huberman. 1994. Qualitative Data Analysis: An Expanded Sourcebook. 2nd Ed. Thousand Oaks, CA: Sage Publications, Inc.

Nyamu-Musembi, C. 2002. "Are local norms and practices fences or pathways? The example of women's property rights," in A.A. An-Na'im (ed.), Cultural Transformation and Human Rights in Africa, pp. 126-150. New York: Zed Books Ltd.
Rah, J.H., C.M. Hasler, J. E. Painter, and K.M. ChapmanNovakofski. 2004. "Applying the theory of planned behavior to women's behavioral attitudes on consumption of soy products," Journal of Nutritional Education and Behavior 36: 238-244.

Richards, L., and J. Morse, 2007. Readme First for a User's Guide to Qualitative Methods, 2nd Ed. Thousand Oaks, CA: Sage Publications, Inc.

Schelling, T. 1960. The Strategy of Conflict. Cambridge: Harvard University Press.

Scholly, K., A.R. Katz, J. Gasciogne, and P. S. Holck. 2005. "Using social norm theory to explain perceptions and sexual health behaviors of undergraduate college students: An exploratory study," Journal of American College Health 53: 153-166.

Shell-Duncan, B., A. Moreau, K. Wander, and S. Smith. 2018. "The role of older women in contesting norms associated with female genital mutilation/cutting: A factorial focus group analysis," PLoS ONE. https://doi.org/10.1371/journal. pone.0199217

Shell-Duncan, B., K. Wander, Y. Hernlund, and A. Moreau. 2011. "Dynamics of change in the practice of female genital cutting in Senegambia: Testing predictions of social convention theory," Social Science and Medicine 73: 1275-1283.

. (2013). "Legislating change? Responses to criminalizing female genital mutilation/cutting in Senegal," Law and Society Review 47(4): 803-835.

Shell-Duncan, B., Y. Hernlund, K. Wander, and A. Moreau. 2010. Contingency and Change in the Practice of Female Genital Cutting: Dynamics of Decision Making in Senegambia. Summary Report on the WHO/NSF Multicountry Study on Behavior Change. https://csde.washington.edu/ bsd/FGC/ Contingency $\% 20$ and $\% 20$ Change $\% 20$ in $\% 20$ the $\% 20$ Practice $\% 20$ of $\% 20$ Female $\% 20$ Genital\%20Cutting.pdf

Thomas, L. 2000. "'Ngaitana (I will circumcise myself)': Lessons from colonial campaigns to ban excision in Meru, Kenya," in B. Shell-Duncan and Y. Hernlund (eds.), Female "Circumcision" in Africa: Culture, Controversy, and Change, pp. 129-150. Boulder, CO: Lynne Rienner Publishers.

Tyler, T. 1990. Why People Obey the Law. New Haven: Yale University Press.

UNICEF. 2005. Changing a Harmful Social Convention: Female Genital Mutilation/Cutting. Florence, Italy: United Nations Children's Fund (UNICEF).

2013. Female Genital Mutilation/Cutting: A Statistical Overview and Exploration of the Dynamics of Change. New York: UNICEF.

Vogt, S., N.A.M. Zaid, H.E.F Ahmed, E. Fehr, and C. Efferson. 2016. "Changing cultural attitudes towards female genital cutting," Nature 538: 506-509. doi:10.1038/nature20100 


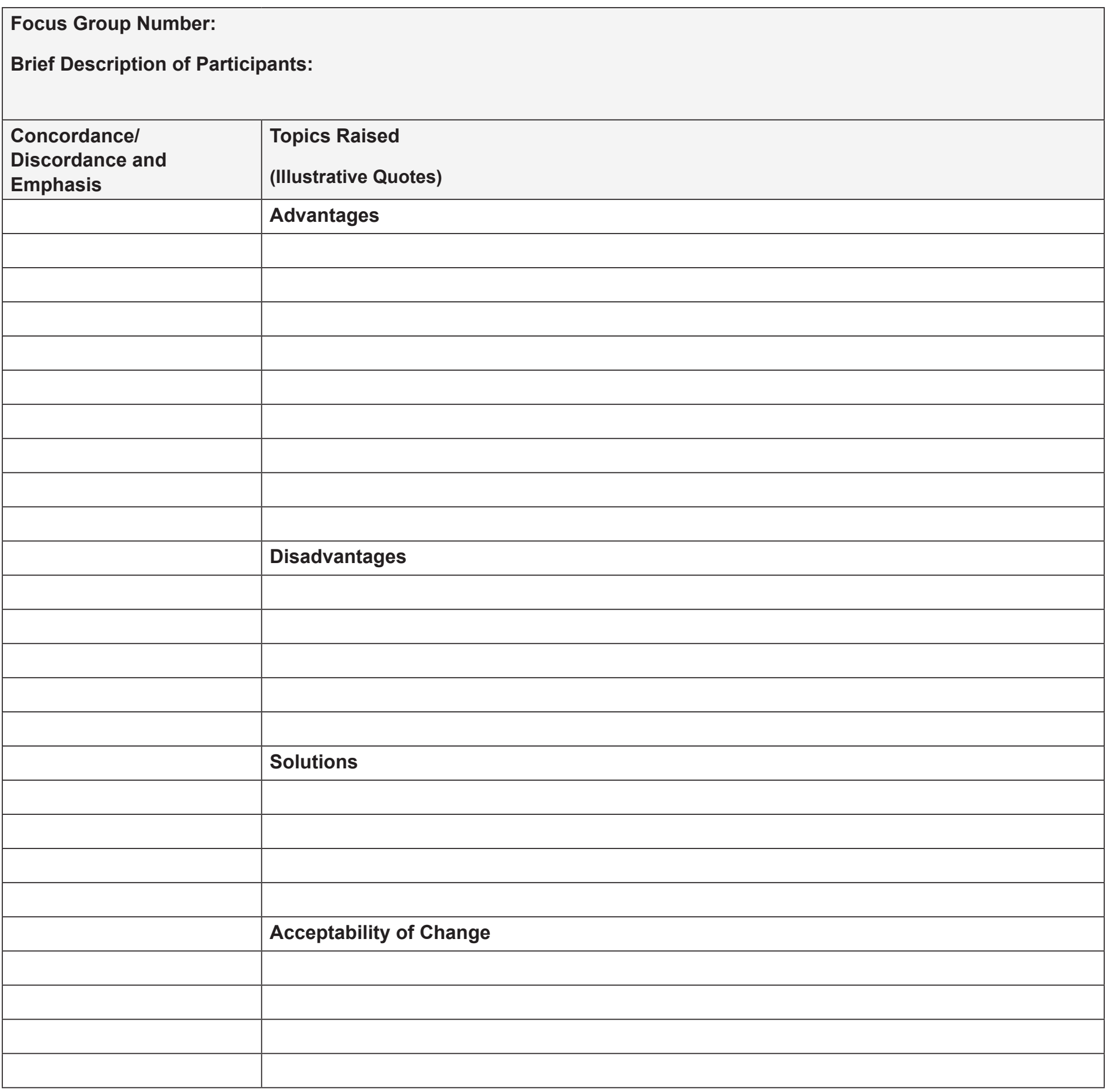


Older women (late 30s, early 40s)

Rural Senegal

Practiced female circumcision-but some say now abandoned

LOTS of AMBIVALENCE

\begin{tabular}{|c|c|}
\hline & Advantages \\
\hline++ & Tradition-found it from our grandmothers \\
\hline \multirow[t]{2}{*}{++} & Training-learn how to behave at circumcision camp \\
\hline & $\begin{array}{l}\text { Three: It was a tradition practiced by our grandparents; that's why we also practiced it. We found it. If they were } \\
\text { circumcised, they embraced it, performed their tradition. Second, circumcised girls also were able to learn from the } \\
\text { circumcision camp how to behave. }\end{array}$ \\
\hline \multirow[t]{5}{*}{++++} & $\begin{array}{l}\text { Respect-"know the eye"; learn to show respect to mothers, also to fathers; show older women respect; display } \\
\text { subservience; know morals }\end{array}$ \\
\hline & $\begin{array}{l}\text { One: The girl was able to know what she did not know-if she wasn't respecting her mother, she would be taught to } \\
\text { respect her mother. She would also be able to know how to behave and to know what it means when someone gazed } \\
\text { at her. }\end{array}$ \\
\hline & $\begin{array}{l}\text { Five: You know, when a girl doesn't know anything, she will have no morals, but when she is circumcised she is taught } \\
\text { and knows something. She will have good morals and know when somebody gazes at you-like the last speaker } \\
\text { mentioned before-when somebody gazes at somebody who is circumcised she knows what he or she means. }\end{array}$ \\
\hline & Seal helps protect virginity before marriage \\
\hline & For men \\
\hline \multirow[t]{5}{*}{++--} & Marriage_-no difference, circumcised and uncircumcised all equal to men; but: \\
\hline & $\begin{array}{l}\text { Before needed to be cut to marry in Mandinka community; elders said if not cut, trouble getting a husband; elders } \\
\text { thought if not cut, trouble getting a husband, but not true. }\end{array}$ \\
\hline & $\begin{array}{l}\text { One: Circumcised and uncircumcised women are all equal to men. They don't have any difference, they all marry the } \\
\text { man. }\end{array}$ \\
\hline & $\begin{array}{l}\text { Five: They are all equal to men. I never heard a man saying he has different feelings about a circumcised or } \\
\text { uncircumcised woman. }\end{array}$ \\
\hline & $\begin{array}{l}\text { Two: Elders saw it as if they didn't circumcise their girls; they might get a husband if they get old. This was their } \\
\text { problem. Our generation is different. This was their perception, but we are not worried now if we don't circumcise girls. } \\
\text { Daughters know morals }\end{array}$ \\
\hline \multirow[t]{3}{*}{+} & Co-wife relations-insult \\
\hline & $\begin{array}{l}\text { Two: If there would be any advantage, it would be on the side of the woman, not the husband. This would be between } \\
\text { co-wives. It would enable circumcised woman to respond to her co-wife when quarreling. }\end{array}$ \\
\hline & Disadvantages \\
\hline \multirow{5}{*}{$\begin{array}{l}+ \\
+ \\
+\end{array}$} & For women \\
\hline & Nurse girls back to health, and deal with health problems \\
\hline & If sealed, need to remove seal before marriage \\
\hline & For men \\
\hline & Expense - pay for circumcision fee, slaughter animals, buy food \\
\hline
\end{tabular}




\begin{tabular}{|c|c|}
\hline & olutions \\
\hline++-- & 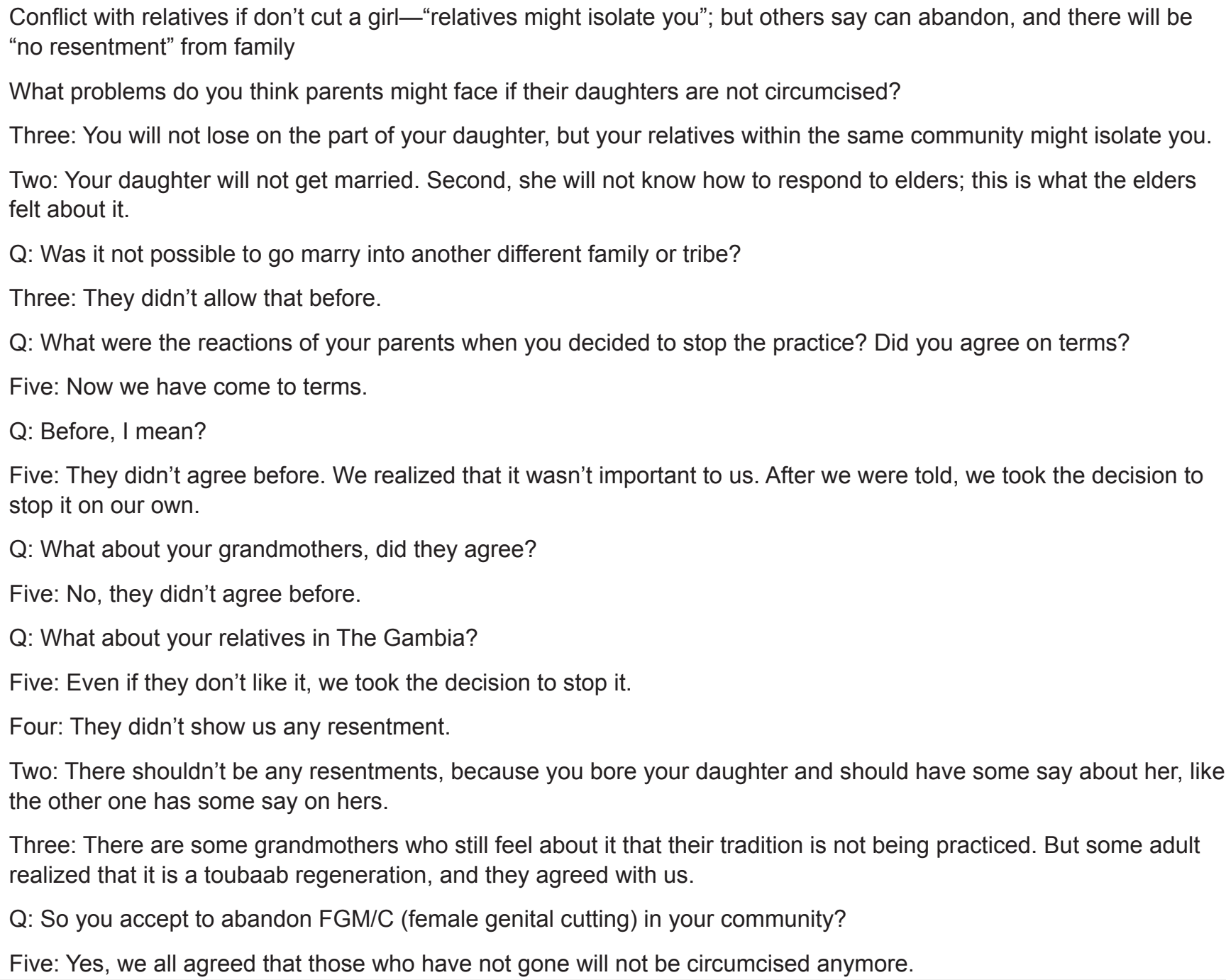 \\
\hline++- & $\begin{array}{l}\text { Abandoning FGM/C: Tostan taught us to leave the practice; we all agreed to stop female circumcision; we are now } \\
\text { aware (not specific about what) and have abandoned } \\
\text { Some people have not stopped } \\
\text { Some still practice in secret } \\
\text { Sealing is a problem, but milder female circumcision is OK }\end{array}$ \\
\hline++-- & $\begin{array}{l}\text { Health issues: ambivalence on obstetrical issues; sealed women have trouble with delivery (and this is why we } \\
\text { decided to stop); can kill during delivery } \\
\text { Uncircumcised women have trouble with delivery: for uncircumcised women, pressure makes the clitoris burst }\end{array}$ \\
\hline
\end{tabular}

Source: Senegambia Behavior Change Study on Female Genital Cutting 


\section{APPENDIX C. SAMPLE DESCRIPTIVE MEMO}

\section{Upholding Social Hierarchy}

\section{Subthemes:}

Respect for elders, for men

Training/know the eye; signals subservience in social hierarchy

Women's hierarchies_-power of elder women over younger women, inclusion in social networks

But who has the authority to challenge decisionmakers (intergenerational)—contested (when wife defied husband's wish to not cut daughter, the girl's hair fell out-moral transgression (not obeying husband) created vulnerability; some say fathers not involved (hands-on) in women's business, but have veto power; can younger women speak against elders without causing grievous disrespect?

1. Challenge in context of interethnic (FGM/C-discordant) $)^{2}$ families

2. Other relatives "taking girls"

In addition to the importance of honoring tradition, a theme that emerged across all focus group discussions (FGDs), but especially among elder women, centered on the importance of displaying respect to elders. The notions of tradition and respect are closely intertwined, and a central way of honoring ancestors is by upholding their traditions. Indeed, an important element of displaying respect is to not question the wisdom of elders, and hence not challenge tradition. The issue of respect, however, also permeates all social relations within the extended family and community, and the training that traditionally accompanied FGM/C strongly emphasized instruction on how to display respect to elders. As Ahmadu (2005: 58) explains, "on one hand the pain and hardship that girls undergo was said to harden and prepare them to be strong and self-assertive in their marital homes. On the other hand, female elders also stressed that through initiation young girls are taught the art of subordination to their husbands, their husband's brothers, and, importantly, to their future mothers-in-law." Physical cutting was accompanied by seclusion in circumcision camps in the bush where girls received training on moral conduct and etiquette, often described as having come to "know the eye." This term refers to having become indoctrinated into the social hierarchy along lines that include age and gender and being able to display signals of deference and respect, acknowledging their place in the social hierarchy. Girls who "know the eye" are able to communicate their respect to elders though nonverbal signs and are said to be able to behave in a fashion that is socially refined in comparison with uncut women. As such, girls who have been properly trained know the moral conduct that allows them to "stay anywhere":

Yes, [if you are circumcised,] you will have respect, you will know the eye. And it will make you be independent, because of the teachings you undergo during circumcision you will be able to stay anywhere.

—Middle-aged (circumcised) Wolof woman, urban Gambia

Hernlund argues that it is women who have the biggest stake in this hierarchy and who thus actively perpetuate female circumcision. She notes that "[i]n a marriage system involving the young wife moving to her husband's family's home, and becoming subservient to the mother-in-law, there is a 'revolving hierarchy,' i.e., young women endure oppression on their way to becoming matriarchs who have the privilege of oppressing another younger generation of women" (2003: 160). Elsewhere (Shell-Duncan et al. 2011) we have argued that signaling subservience within the women's social hierarchy facilitates entry into the social networks of elder women and confers access to social support and resources (social capital). In the socioeconomic conditions of the Senegambia, where poverty is common, crises frequent, and opportunities scarce, adults rely heavily on social networks to access resources and opportunities to create relationships for sharing and solidarity. Both men and women in the Senegambia rely on extensive networks of friend, acquaintance, and family contacts in a variety of ways: for example, contacts may be used to access job and business opportunities, family may be relied on for childcare or helping to cover expenses, and

\footnotetext{
${ }^{2}$ One parent's family practices female genital cutting and the other does not.
} 
both family and social contacts relied on for public and social support (e.g., in a dispute with another member of the community). Having circumcision in common confers "insider" status and enhances the likelihood that two individuals will form a social connection (the currency of social capital). These "ready-made" connections may be particularly useful to young women, who, upon marriage, face the prospect of leaving the majority of their social connections behind in their natal home, to build their social capital anew in their marital home.

Female circumcision and female networks have an important intergenerational component. Elder women, established in the community and often wealthier, are at an advantage in forming networks with both fellow women and men, and, at the same time, are less likely than younger women (in new marriages, with fewer connections, and with young children) to need to rely on their connections for social or material support. In including a younger woman in her network, an older woman is more likely to be called upon by the new connection for support than she is to be the recipient of support. Some of our qualitative data suggest that, in order to gain entry into women's networks, young women/girls offer their deference or obedience to older women in the network, enhancing the elder's power and standing in the community. Female circumcision signifies that these girls (or their family, on the girls' behalf) will be well-mannered and obedient, subordinate members of the network.

A key source of debate among participants centered on whether recent changes in the way that FGM/C is performed undermines its value in providing training. With no longer having group circumcisions, followed by seclusion in the bush, and even more importantly, with $\mathrm{FGM} / \mathrm{C}$ being done at younger and younger ages, the ability to impart training during initiation has come into question. As one Mandinka grandmother asked, "What training can you give to an infant girl?"

Children of today who are taken as a small child, mostly... their training is lacking. But when they are taken as a fully grown girl-at our time you knew the eye, you would be aware of how to live with people for long and not offend anyone. That is what we call knowing bad from good.

—Mandinka woman, urban Gambia.

And a Sereer woman in Senegal elaborated: "The respect we are talking about, if we look at the generation that we are, we see no benefit. The reason there is no benefit is, in those days of our grandparents, they used to keep us for a month (of training). But in this generation they do not do that."

\section{Authority to question FGM/C}

Given the paramount importance placed on upholding tradition and displaying respect for elders, a key question regarding FGM/C is how and when people can express ambivalence or resistance to the practice. Traditionally, in many communities, circumcision for all girls was basically assumed. The decision to be made was not whether to circumcise, but when and how. Often, elders would designate a time for a large circumcision when enough girls of age to be circumcised had accumulated in the community. The community-wide decision to hold a group circumcision would then instigate decisionmaking at family and individual levels; for example, whether to participate in the group circumcision or to postpone until the next opportunity, or whether to travel or send a girl to a neighboring community to participate in circumcision there.

As large group circumcisions have become less common, decisionmaking regarding when and how to circumcise has shifted to the family, also providing more opportunity to revisit the question of whether (rather than when) a girl will be circumcised. Additionally, with the increase in inter-ethnic marriages, instances of FGM/C-discordant marriages (one parent's family practices FGM/C and the other does not) has complicated decisionmaking. In many instances, ethnicity and FGM/C traditions are passed along paternal lines, but this was not universally the case, and opened ambiguity, debate, and increasingly intense conflict over the authority to make decisions about circumcision of a girl. In FGDs where some members expressed having come to oppose $\mathrm{FGM} / \mathrm{C}$, there was no clear consensus on who has the authority to challenge the practice of $\mathrm{FGM} / \mathrm{C}$, and who has the right or authority to persuade others in their family or community. In only rare instances was decisionmaking made by individuals. Most commonly, numerous members of the extended family — mothers, co-wives, grandmothers, aunts, and fathers—can participate in this decision; where there is conflict, these individuals have different degrees of power (to either prevent circumcision or make circumcision happen). Young mothers commonly express having limited authority to challenge the decisions of elder women: 
They could have circumcised her without telling me about it and I would not say anything because it is her father's tradition and I am just a mother.

-Young Mandinka woman, urban Gambia.

Those who oppose FGM/C could bolster their position by eliciting support from others, including elder female family members, as well as their husbands. Regarding fathers, the extent of their "veto power" seems to vary a great deal from family to family. Some argue that obtaining a father's consent is required, and defying his wishes is a serious moral transgression; others view senior women as having paramount authority, even if they are defying a father's wishes. Decisionmaking in some instances results from achieving consensus among decisionmakers. In other cases, individuals can act against the will of other decisionmakers and have a girl cut despite the opposition of other family members. In particular, when there is a lack of agreement among decisionmakers, those who do not want a girl to be circumcised are often on constant vigil to prevent the girl from being "taken" by family members who have both responsibilities and rights over children in their family, including the right to take a girl to be cut against the will of her parents.

You will see when some people say they will leave it [FGM/C] she will say, "for the circumcision, for me, well, I have left it."Her relatives, you will see a person come and take her by force, and they will take her. And if you [the mother] want to stop this, it will become a problem because they have already taken her.

-Young Mandinka woman, urban Gambia

Older women, well established in the community, assert their power and authority within the community and the family, and in particular have a great deal of authority over junior women in their extended family. As young women marry and move to their marital home, FGM/C serves to signal "insider" status among women in the extended family. The authority of elder women stems not only from their roles as guardians of traditions regarding FGM/C, but also from their extensive knowledge on various aspects of childrearing and child well-being.

But it is elder women who most commonly express ambivalence or opposition to FGM/C.

Custodians of tradition, but also open to change.

Source: Senegambia Behavior Change Study on Female Genital Mutilation/Cutting (FGM/C) 


\section{Social hierarchy and "knowing the eye"}

A theme that emerged across all focus group discussions (FGDs) centered on the importance of displaying respect to elders as a means of upholding social hierarchy (Table A1). One important mechanism for displaying respect is to signal subservience, commonly described as "knowing the eye." This term refers to being able to communicate respect for elders through nonverbal signs, and more generally behave in a fashion that is socially refined in comparison with uncut women. Acknowledgment of social hierarchy makes explicit the power structure that permeates in many realms of social life, including the authority to question the practice of $\mathrm{FGM} / \mathrm{C}$.

TABLE A1. SUMMARY MATRIX OF THEMES RELATED TO THE OVERARCHING THEME OF UPHOLDING SOCIAL HIERARCHY

\begin{tabular}{|l|c|c|c|c|c|c|}
\hline \multirow{2}{*}{} & \multicolumn{2}{|c|}{ Urban Gambia } & \multicolumn{2}{c|}{ Rural Gambia } & \multicolumn{2}{c|}{ Rural Senegal } \\
\cline { 2 - 7 } & $\begin{array}{c}\text { Younger } \\
\text { women }\end{array}$ & $\begin{array}{c}\text { Older } \\
\text { women }\end{array}$ & $\begin{array}{c}\text { Younger } \\
\text { women }\end{array}$ & $\begin{array}{c}\text { Older } \\
\text { women }\end{array}$ & $\begin{array}{c}\text { Younger } \\
\text { women }\end{array}$ & $\begin{array}{c}\text { Older } \\
\text { women }\end{array}$ \\
\hline Respect for elders & + & + & + & + & + & + \\
\hline Training (to "know the eye") & + & + & + & + & + & + \\
\hline $\begin{array}{l}\text { Authority to challenge } \\
\text { FGM/C }\end{array}$ & - & $+/-$ & - & $+/-$ & & $+/-$ \\
\hline
\end{tabular}

+ positive consensus

+/- divergent views

-negative consensus

Blank - theme not raised

The training that traditionally accompanied FGM/C strongly emphasized instruction on how to display respect to elders. As Ahmadu explains, "on one hand the pain and hardship that girls undergo was said to harden and prepare them to be strong and self-assertive in their marital homes. On the other hand, female elders also stressed that through initiation young girls are taught the art of subordination to their husbands, their husband's brothers and, importantly, to their future mothers-in-law" (Ahmadu 2005: 58). Women who "know the eye" have been indoctrinated into the social hierarchy and know to signal deference to those in higher positions.

Yes, [if you are circumcised,] you will have respect, you will know the eye. And it will make you be independent, because of the teachings you undergo during circumcision you will be able to stay anywhere.

—Older (circumcised) Wollof woman, urban Gambia

Now that FGM/C occurs at early ages and in the absence of seclusion, training on properly displaying respect is carried out by women in the extended family throughout a girl's childhood. Given that social order based on hierarchies of power is anchored in filial piety, a key question regarding FGM/C is, who has the authority to challenge the practice? In the past, circumcision for all girls was basically assumed. The decision to be made was not whether to circumcise, but when and how. Often, elders would designate a time for a large circumcision when enough girls of age to be circumcised had accumulated in the community. The community-wide decision to hold a group circumcision would then instigate decisionmaking at family and individual levels; for example, whether to participate in the group circumcision or to postpone until the next opportunity, or whether to travel or send a girl to a neighboring community to participate in circumcision there.

As large group circumcisions have become less common, decisionmaking regarding when and how to circumcise has shifted to the family, also providing more opportunity to revisit the question of whether (rather than when) a girl will be circumcised. Additionally, with the increase in interethnic marriages, instances of FGM/C-discordant marriages (one parent's family practices FGM/C and the other does not) has complicated decisionmaking. While custom dictates that ethnicity and FGM/C traditions 
are inherited patrilineally, the reality is much more complex and situationally negotiated. This ambiguity has begun to shift the bedrock of women's collective identities and moral personhood, sparking familial debates about modifying or ending FGM/C. Commonly numerous members of the extended family — mothers, co-wives, grandmothers, aunts, and fathers-participate in decisionmaking; where there is conflict, these individuals have different degrees of power (to either prevent circumcision or make circumcision happen). Young mothers commonly expressed having limited authority to challenge the decisions of older women:

They could have circumcised her without telling me about it and I would not say anything because it is her father's tradition and I am just a mother.

-Young Mandinka woman, urban Gambia.

Those who oppose FGM/C could bolster their position by eliciting support from others, particularly senior female women who have power and authority within the community and the family, and in particular have a great deal of authority over junior women in their extended family.

Hernlund (2003) predicted that because senior women have the biggest stake in the intergenerational hierarchy of among women, they would be more likely than younger women to support the perpetuation of FGM/C and to resist those who challenge the practice. Our findings do not support this assertion. In discussions among younger women, particularly in The Gambia, there was agreement that they lack the authority to question norms associated with FGM/C, as it represents an unacceptable challenge of the authority of older women. By contrast, older women commonly debated among themselves about shifting social circumstances and whether or how traditions, including FGM/C, should be modified to uphold cultural values in light of social change.

Source: Senegambia Behavior Change Study on Female Genital Mutilation/Cutting (FGM/C) 


\section{ACKNOWLEDGMENTS}

This reference guide draws on the experiences implemented in the Senegambia Behavior Change Study on Female Genital Cutting. Dr. Ylva Hernlund provided valuable input with study design, data collection, and data processing. We would like to acknowledge the important contributions of our hard working and dedicated field team in Senegal and The Gambia: Alhagy Bah, Sally Bojang, Modou Dem, Ebrima Jallow, Serreh Jebang, and Naisatou Konteh. For this reference guide, we draw on the work that resulted in the following publication: "The role of older women in contesting norms associated with female genital mutilation/cutting: a factorial focus group analysis." This manuscript, written by Bettina Shell-Duncan, Amadou Moreau, Katherine Wander, and Sarah Smith, was published in PLoS ONE in 2018, and is available online: https://doi.org/10.1371/ journal.pone.0199217. 
Evidence to End FGM/C: Research to Help Girls and Women Thrive generates evidence to inform and influence investments, policies, and programmes for ending female genital mutilation/cutting in different contexts. Evidence to End FGM/C is led by the Population Council, Nairobi in partnership with the Africa Coordinating Centre for the Abandonment of Female Genital Mutilation/Cutting (ACCAF), Kenya; the Global Research and Advocacy Group (GRAG), Senegal; Population Council, Nigeria; Population Council, Egypt; Population Council, Ethiopia; MannionDaniels, Ltd. (MD); Population Reference Bureau (PRB); University of California, San Diego (Dr. Gerry Mackie); and University of Washington, Seattle (Prof. Bettina Shell-Duncan).

\section{POPULATION} COUNCIL

Ideas. Evidence. Impact.

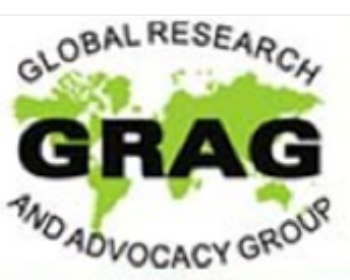

Leading Innovative Research

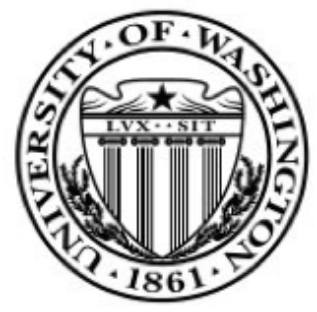

The Population Council confronts critical health and development issues-from stopping the spread of HIV to improving reproductive health and ensuring that young people lead full and productive lives. Through biomedical, social science, and public health research in 50 countries, we work with our partners to deliver solutions that lead to more effective policies, programs, and technologies that improve lives around the world. Established in 1952 and headquartered in New York, the Council is a nongovernmental, nonprofit organization governed by an international board of trustees. www.popcouncil.org

GRAG is dedicated to the promotion and protection of minorities' rights to safeguard their well-being. This is initiated by the introduction of effective programs tailored to the needs of the target communities. Through strategic and applied research, training, and advocacy, GRAG seeks to identify and target areas of improvement for effective program initiatives. Our team is intent on engaging communities to make informed decisions regarding their sexual and reproductive health, family planning, and nutritional needs. We therefore strive to initiate programs that strengthen the capacities and protection of vulnerable populations by helping them access the necessary information and services they require. http://globalresearchandadvocacygroup.org

The University of Washington is one of the world's preeminent public universities. Our impact on individuals, our region, and the world is profound - whether we are launching young people into a boundless future or confronting the grand challenges of our time through undaunted research and scholarship. We turn ideas into impact and transform lives and our world. www.washington.edu

Suggested Citation: Shell-Duncan, B., Moreau, A., Wander, K., and Smith, S. (2019). "Reference Guide: Factorial focus group analysis methods for studying social norm change." Evidence to End FGM/C: Research to Help Girls and Women Thrive. New York: Population Council.

For additional information, contact:

Bettina Shell-Duncan at bsd@uw.edu

Please address any inquiries about the Evidence to End FGM/C program consortium to:

Dr Jacinta Muteshi, Project Director, jmuteshi@popcouncil.org

(c) 2019 The Population Council, Inc.

Funded by:

$\Delta V$

ThN

UKaom the British people

This document is output from a programme funded by UK Aid from the UK government for the benefit of developing countries. However, the views expressed and information contained in it are not necessarily those of, or endorsed by the UK government, which can accept no responsibility for such views or information, or for any reliance placed on them. 